\title{
Short communication The dangers of complementary therapy
}

Mike Baum

Cotman Close, London, NW11 6PT, UK

Corresponding author: Mike Baum, michael@mbaum.freeserve.co.uk

Published: 20 December 2007

This article is online at $\mathrm{http}: / /$ breast-cancer-research.com/content/9/S2/S10 (c) 2007 BioMed Central Ltd

\section{Introduction}

The Oxford English Dictionary defines the word 'complementary' as, "that which completes or makes perfect, or that which when added completes a whole." In other words, although modern medical science struggles to make patients get better, complementary medicine helps patients to feel better and, who knows, by feeling better the act of healing itself may be complemented. It bothers me not at all if the touch of the healer or the hand of the therapeutic masseuse is guided by strange belief systems that are alien to me, provided the intention is to support the clinician in his or her endeavours rather than compete in the relativistic marketplace of ideas. If that is the case, then how can complementary medicine be dangerous?

I list here my concerns that will be expanded upon in my talk: complementary medicine is used as a cloak for alternative medicine; it does not make the patient feel better; it allows placebos in through the back door; it may interact with effective drug therapy; it is a waste of precious resources; and it subverts science and is an insult to intelligence.

I can summarize the first three concerns very simply. Many proponents of alternative medicine attempt to achieve acceptability by claiming that they are complementary practitioners and then, via the back door, they attempt to subvert the treatments offered by the medical practitioners. They may also claim to make the patient feel better, but they never trouble themselves by measuring the quality of life of their clients. Even if their clients do feel better, this more than likely results from the use of placebos - a practice that is considered unethical by the medical profession.

Frequently used herbal remedies are either of no proven value or may interact with conventional drug therapy; example interactions include those of Ginkgo Biloba with aspirin and warfarin (coumadin), St. John's wort with antidepressants, and Ginseng with warfarin. These remedies also do not come cheap and may be a waste of public or private resources. However, my main concern is that so many of these implausible remedies are based on absurd beliefs that are
Breast Cancer Research 2007, 9(Suppl 2):S10 (doi:10.1186/bcr1808)

allowed, slowly, to poison our minds and subvert rational thinking. I wish to expand at length on this, using homeopathy a popular 'complementary medicine' - as an example.

\section{The nature of absurd belief systems}

Take homeopathy for instance. It is based on the principle of 'like cures like' and the concept of memory of water. The 'like cures like' principle holds that if a substance causes certain symptoms in healthy volunteers (like onions cause a runny nose), then this substance constitutes an effective treatment for conditions associated with those symptoms (for instance, an onion cures a common cold). The second principle posits that serial dilution in combination with vigorous shaking of a substance (homeopaths call this 'potentation') does not render that substance less but more powerful. Thus, the most 'potent' homeopathic medicines are so highly dilute that they do not contain a single molecule of the original substance. These axioms are not only out of line with scientific facts but are directly opposed to them; if homeopathy is correct, then much of physics, chemistry and pharmacology must be incorrect. It is therefore not an option to have an open mind about homeopathy or similarly implausible forms of alternative/ complementary medicine, for example Bach Flower remedies, spiritual healing and crystal therapy. I think that a belief in homeopathy exceeds the tolerance of an open mind.

We should start from the premise that homeopathy cannot work and that positive evidence reflects publication bias or design flaws until proven otherwise. If not, then we must believe that water has a selective memory. Thus far, homeopathy has failed to demonstrate efficacy in randomized controlled trials (RCTs) and systematic reviews of well designed studies. Homeopathic physicians appear to clutch on to a series of poorly designed studies to retain their credibility or they claim that the RCT is an inappropriate methodology with which to assess their belief system in the name of postmodern relativism. Should we keep an open mind about astrology, perpetual motion, alchemy, alien abduction and sightings of Elvis Presley? No, and I am happy to confess that my mind has closed to homeopathy in the same way. 
Here is why. Homeopathy is based on an absurd concept that denies progress in physics and chemistry. Homeopathy is only advocated for self-limiting conditions, for example it cures a cold in 7 days that would otherwise take a week. Do even homeopaths rely on their treatments for cancer and other life-threatening conditions? There are no reported major 'advances' in homeopathy. Finally, homeopathic principles are 'bold conjectures'. There has been no spectacular corroboration of any of its founding principles.

Yet homeopaths remind us of Galileo's battle with the dogma of his day and how in the fullness of time this heretic was proven right. The Galileo argument is a syllogism, a kind of logical argument in which one proposition (the conclusion) is inferred from two others (the premises) of a certain form. For example, Van Gogh was a great artist not recognized in his lifetime. I am an artist who has so far not sold a painting, ergo 'I am great'. After more than 200 years we are still waiting for homeopathy 'heretics' to be proven right, whereas Galileo's genius was recognized not long after his death. The true sceptic therefore takes pride in closed mindedness when presented with absurd assertions that contravene the laws of thermodynamics or deny progress in all branches of physics, chemistry, physiology and medicine. As the late lamented Petr Skrabanek once stated, "if your mind is too open your brain slides out." Well my brain is too precious an organ to be hazarded in this way, and my mind is tightly closed when asked to consider the possibility that homeopathy (crystal healing, Bach's flowers, psychic surgery and so on) is anything other than a placebo offered by a kindly practitioner with ample time at their disposal.

\section{Acknowledgement}

This article has been published as part of Breast Cancer Research Volume 9 Supplement 2, 2007: Controversies in Breast Cancer. The full contents of the supplement are available online at http://breastcancer-research.com/supplements/9/S2. 